particular gas in the way of gasoline production with a given plant equipment. The Bureau is making a study of these methods of examination. Perhaps the simplest of the tests applied at the present time consists in the determination of the density of the gas or in shaking the gas with some solvent such as olive oil, cotton seed oil, clairolene oil, etc., in which the higher paraffin hydrocarbons are more soluble than the lower. It was found, for instance, that by shaking I $00 \mathrm{cc}$. of a gas from which a very high yield of gasoline is obtained in $35 \mathrm{cc}$. of clairolene oil that 80 per cent. of the gas dissolved in the oil. Pittsburgh natural gas lost only is per cent. of its volume when treated in the same way. The latter gas cannot be used for the commercial production of gasoline. Pittsburgh natural gas has a density of 0.64 compared to air as I at $0^{\circ} \mathrm{C}$ and $760 \mathrm{~mm}$. pressure while it has been found that natural gases having a density of 0.86 do produce gasoline. The author has found, however, that other gases having the same density and absorption number contain different proportions of the paraffin hydrocarbons so that it cannot be stated that all natural gases having a density of 0.86 will produce gasoline.

The Bureau has issued one publication having to do with the properties of liquefied natural gas. In the production of gasoline a very great waste has occurred, because, in order to make condensates safe for shipment, the lighter products have been allowed to evaporate. The confinement of the material in iron cylinders for use as a bottled gas is now receiving attention. ' A gas is produced which has a heating value of at least 2200 B. t. u. per cubic foot, and a candle power of about 45 when burned as a naked flame at the rate 5 cubic feet per hour. The use of a mantle will, of course, increase this lighting effect greatly. In order to bring this means of utilizing natural gas to your attention, Mr. I. C. Allen and the writer simply bottled in strong cylinders the condensate obtained by applying a pressure of about $500 \mathrm{lbs}$. to the square inch and a temperature of $0^{\circ} \mathrm{C}$. to crude gas obtained from wells at Follansbee, W. Va. There are some here who could do the same with their casing head gas which is at present going to waste. Once bottled it is only necessary to slightly crack the valve to obtain a supply of true gas.

In experiments conducted at the Bureau, the gas was passed through a small meter, and then burned in a Junker calorimeter. Samples of the gas were also analyzed. By taking the gas from the bottom of the tank its composition remained uniform throughout the test. In the case of the exceedingly rich gas obtained at Follansbee, W. Va., about 50 cubic feet of gas per gallon of liquid were realized. For the better control of the gas as it issued from the bottle, a reducing valve was attached.

The Bureau has, of course, viewed this manner of utilizing natural gas from the standpoint of a purely technical investigation, with no axe to grind, except a step in the conservation of natural resources and believes that some of the gas at present going to waste will eventually be used this way. Millions of people are so situated that gas is not used by them, but if a bottled gas sold at a reasonable price becomes available, the outlet for the material will be large. The Bureau has recently learned that one company is already in the field for the purpose of exploiting the liquid gas. They have named their product "Gasol."

Another means of utilizing natural gas has been tried in that attempts have been made to prepare substitution products, principally chloroform, by the action of chlorine upon methane. Although seemingly difficult to do commercially, one cannot say that such will always be the case. Mention is made of these processes simply as showing that the entire utilization of natural gas may not always be along the line of combustion processes.

Probably in but few instances has surface combustion been applied in this country as yet to the use of natural gas. A 92 per cent. efficiency in the case of gas-fired boilers obtained by Prof. Bone is a noteworthy advance and opens up a wide field for the saving of gas in combustion processes. An installation is not complicated or costly.

In the every-day use of natural gas for domestic purposes, saving may be accomplished if appliances are used which are best suited to the economical combustion of natural gas. Natural gas burners require more air than coal gas burners, and if the same burner regulation is used for natural gas that works well with coal gas, the former is not being completely burned. Some natural gas appliances in use are notoriously inefficient. Progressive gas men should give this question of proper appliances serious consideration. Natural gas is cheap and the tendency may be to use more for any particular purpose than is necessary. A campaign along this line, which would result in a smaller consumption of gas per family, should help remove some of the objection to the inevitable rate rise.

In conclusion, it can be stated that the Bureau of Mines wants to do all it can to conserve the natural gas supplies. Great care must be exercised in the use of deposits which are only bubbles and which when punctured become exhausted. Reckless waste of the gas in the field should be prevented by legislation, and every effort should be made toward the education of all concerned that they may realize the necessity of conserving the supply. It is believed that the Bureau of Mines can do some efficient work along the latter. line.

Bureau of Mines, WASHINGTON.

\section{A PLAN FOR THE SUPPORT OF CHEMICAL RESEARCH AND FOR THE BETTER TEACHING OF INDUSTRIAL CHEMISTRY.}

By John STEWart.

Received April 19, 1912.

The writer has read with some interest several papers and editorials appearing in the journals of the American Chemical Society during the past year on the subject of the teaching of industrial chemistry and the conservation of chemical research, especially that kind of chemical research which has to do with the applica- 
tion of chemistry to the industries. These articles are some of the effects of the increasing competition for the places held by chemists, and the unsatisfactory condition of the industrial chemist in relation to the business of which he is a part. The theme of these articles has been: What ought we to do? What can we do? What should we do to improve the condition of the industrial chemist, to increase his power for rendering useful and efficient service, and through him to benefit the business with which he is connected?

These articles have all had one important point in common, but there the uniformity ends, for each has proposed a different method of solving the problem. Some of these articles have been written by teachers of industrial chemistry who have not had actual, practical experience in the application of chemistry to the industries, if one may judge correctly from the general tone of certain statements made. But it is not intended to offer any criticism of articles heretofore published on this subject, they being in the main thoughtful and ably prepared papers. What we now need is a uniform plan of action. We have a certain unity of purpose. If we can connect with this a plan of solving the problem, which meets with general approval from our Society, or at least with the approval of a good working majority of the Division of Industrial Chemists, and will then work unitedly in accordance with this plan we should be able to accomplish some desirable results.

It is the desire of the writer to aid, if possible, in this movement toward a uniform plan of action. In order to get unity of action it is evident that we must confine ourselves to general principles, and leave details to be solved in accordance with the views of individuals and the necessities of local conditions.

The best proposition that has so far been advanced looking toward the amelioration of the condition of industrial chemistry appeared in the November, I9II, issue of THIS JoURNAL. In that number there appeared a very able editorial entitled "Facilities for Industrial Research." The author of that editorial exhibits thorough, first-hand knowledge of the conditions with which he deals. He advances as a fundamental proposition the following state ment: "But there is one field which is richer in the promise of results than all others combined; a field which will yield a more immediate, direct, and tangible return to our own industry, our own profession, and to our own members; and that is in recognizing the necessity of systematic study of industrial problems and throwing the undivided infuence of this Society into the establishment and maintenance of laboratories equipped to answer the eternal questions arising as a result of industrial progress."

This quotation contains at least three general principles: Ist, industrial chemical problems require systematic study; and, there should be properly equipped laboratories for such study; 3 rd, the American Chemical Society should work as a unit toward the establishment of such laboratories. It is not difficult to conceive that some business men who profit by the application of chemistry to industry would object stren- uously to some or all of them. But it is difficult to conceive that any member of the American Chemical Society, who has a sound, thorough training in chemistry, should object to any one of them.

But there must be some other general principles to which a large body of us can agree; otherwise there can not be any further progress toward a solution of the problem. A few of them appear to be of such general acceptability that they will command the support of a large portion, at least, of the American Chemical Society.

In the first place, the establishment of chemical laboratories is generally a business proposition and they are and must be directed and controlled from a business point of view. Of course there is a large portion of the membership of the Society who dislike the term "business," and who prefer to consider their occupation a "profession" rather than a "business." Yet, if the signs of the times are read aright more and more "professional" men are going into business, and "business" is going to be the great "profession" of the not far distant future. In the second place, a business proposition must be a self-supporting proposition, otherwise it sooner or later passes from the sphere of human action. Hence, a chemical research laboratory must be a self-supporting institution.

Some business men who are reaping profits from chemical industries do not act as if they thought chemical research a paying business proposition. They appear to regard the research chemist in much the same way that many research men regard the business man. Both think the other capable of being improved upon to a very marked degree. Some business men of this type even expressly forbid the chemist in their employ to do any experimenting of any kind, and their laboratories are very poorly built, the equipment being scant and the cheapest the market affords, and chemical literature unknown, the laboratories even being without a book of tables for calculations. To this type of business man, chemistry is a two times two are four proposition; every professed chemist is expected to answer off-hand any question concerning the chemistry of any phenomena which may occur. This is not intended as a libel or a joke on the business man but is a clear, cold statement of fact.

Again, some business men recognize that chemical research, if properly directed, may be made a good paying business investment. Some of this type have established research laboratories in connection with their business.

A review of the history of the business man's treatment of the chemist is not flattering to the chemist, but, nevertheless, the business man is slowly but surely being forced (by competition) to change his methods; and the future of industrial chemistry really looks very much brighter than the past. In the judgment of the writer, the business men who manage chemical industries are not going to establish research laboratories in connection with such industries, with any great degree of rapidity. That more of such laboratories will be established is practically certain, but the process will be a slow, hard-fought one. 
Now, on the other hand, how do we chemists regard research? Do we consider it a paying proposition from the business point of view? Undoubtedly most of us do, but we recognize the profits to be, in many cases, very remote; so remote, in fact, that the business man takes no chances on them. And again, we could probably all designate some pieces of work, done usually by "the other fellow" as "research work," which we would hesitate to dignify by that term. Then, too, if we regard research as a business proposition, there is no doubt that it should be directed along the lines of the most immediate and the greatest need. Glancing over Chemical Abstracts, we find that a large portion of the space is devoted to abstracts of research papers relating to organic chemistry: out of some I00,000 known compounds, about 75,000 of them are synthetic. Vegetable physiological and animal physiological chemistry are comparatively neglected, yet these are the fields where the natural organic compounds occur. The reason for their comparative neglect is apparently the greater difficulty of research in these lines. We need more and better research into the fundamentals of chemistry, but we also need, and need more immediately and to a greater degree, research into the problems attending the applications of chemistry to industry.

If we admit that the establishment of research laboratories is a business proposition and that the research should be self-supporting, then how is the money for the development and maintenance of the research institution going to be directed into the research treasury. Information of a certain kind is the one valuable asset of a research institution; but knowledge has a peculiar habit of leaking out, so that its benefits get more or less generally diffused among the public without any direct expense to the public. Evidently the public should pay for the development and maintenance of useful research; that is, the State Governments and the General Government should establish and maintain needed research laboratories, and it would seem that the American Chemical Society must necessarily act as a unit toward influencing the public to perform its duty.

But part of the public will object to this kind of procedure, and the strength of this objection is a very serious obstacle in the path of those who favor the move. This difficulty could be partially avoided by the adoption of a plan which appears to the writer to be a better one than that of securing annual or biennial appropriations from Congress or from State legislatures.

Let this society exert its undivided influence to prevail upon Congress and State legislatures to appropriate a sufficient fund for the establishment of research institutions in each State, these research institutions to be established in connection with State universities or agrioultural and mechanical colleges, more appropriately with the latter but probably with both. Then let the Government or State aid cease but let the institution remain Government or State property, concerning the administration of which an annual report should be made by those in charge. Let the fund provided be invested in a full fledged manufacturing plant of a kind appropriate to local conditions. Let this plant be managed and operated on a business basis just as if it were the property of a private corporation, but instead of paying dividends on the original investment let the profits be used to maintain needed chemical, physical, and mechanical research laboratories and help support the teaching part of the institution with which it is connected. In this way the taxation of the people for the support of education would be diminished, and their educational facilities improved. It would also enable the people to take an effective part in the prevention of extremely high and extortionate prices for goods, which private corporations are sometimes supposed to levy. The plan would meet with opposition, but most Governmental activities which threaten to reduce profits, for the benefit of the people, are antagonized by the business men affected. In this way, the business which benefits by scientific research would pay the expenses. of scientific research, which is not altogether true of present conditions.

To illustrate the plan, let me say that the agricultural college of a certain state is located in a rich agricultural region in which several sugar factories are flourishing. If this agricultural college were provided with a million dollar fund, it could purchase, possibly, a sugar factory already in successful operation, or if terms of sale by the owners could not be secured on a satisfactory basis, the college could build a new factory (capable of handling 600 tons of beets per day) at a cost of approximately $\$ 350,000.00$ to $\$ 400,000.00$. The balance of the original fund would be required as a working capital. A factory of this capacity would yield an annual profit of about $\$ 200,000.00$, which could be: very appropriately used to pay for the support of education and research.

On this plan, the educational institutions of the country would have the facilities as well as the expert knowledge, both practical and theoretical, to teach successfully industrial chemistry, mechanical engineering and business administration, without "aping" industrial activities on a small scale. No one institution could teach the practice of the whole field of industrial chemistry, but all could teach the general theory as now and each one would be specially prepared to teach one phase of industrial chemistry: in general it is in only one phase of industrial chemistry that the industrial chemist is going to become really expert. Degrees for industrial chemists might be put on the same basis as the Ph.D., or otherwise as the educational institutions should see fit.

Some business men would oppose this plan. But business men are already encroaching upon the field of higher education and research. They are teaching. their employees the theory as well as the practice of the particular business in which they are engaged and are at the same time paying the employees wages. whereby they are enabled to live while being educated. They are also establishing research laboratories in connection with their business for the study of problems which have to be met and solved. But they are doing this not for the purpose of benefitting their 
employees or the general public, but solely for the purpose of increasing profits, or saving themselves from being driven out of business by their competitors who are learning cheaper and better ways of doing things, and who are cutting prices as a consequence. It would seem, therefore, that the scientific men could very advantageously to themselves commence to encroach upon the particular field of the business man. When the scientific man gets in control of business, the scientist will fare better in the business world; but only in so far as the scientist gets control, can he hope for much consideration from the business man.

It would seem to the writer also that the American Chemical Society could, very advantageously to itself, endow itself with a fund of say $\$ 1,000,000$, with which it could go into business for itself. A fund of this size would require about a $\$_{200}$ investment from each member. By proper management the Society could have a considerable annual income to devote to research, the cheapening of publications to the members, or otherwise as desired. There is plenty of business and technical ability in the Society to engineer such a plan to success. The Division of Industrial Chemists is composed of men who are specially fitted for the carrying out of a plan like this in certain fields at least. This kind of a proposition, proposed and carried out by a great body of scientific men, would probably be free from the suspicion that it was only "a stock jobbing proposition." The plan, once in successful operation and fairly administered, would doubtless prove very beneficial to the Society.

LOGAN, UTAH,

\section{CURRENT INDUSTRIAL NEWS}

By W. A. HAMOR.

\section{THE MANUFACTURE OF NITRATES FROM THE ATMOSPHERE.}

E. K. Scott states (Nature, 89,463 ) that although the first experimental plant for the manufacture of calcium nitrate by the direct process of Birkeland and Eyde was started only nine years ago, already the Norwegian Hydro-Electric Nitrogen Co., which controls the Birkeland-Eyde patents, has installations aggregating 200,000 horse-power at work and probably by 1916 another 300,000 horse-power will be at work. The other electrically produced nitrogenous manure, calcium cyanamide, is manufactured by a more indirect method invented by Franck and Caro, and its manufacture is not confined to Norway. The following table gives the principal installations, and it may be noted that, although the first one on a commercial scale was erected at Piano d'Orto, in Italy, only eight years ago, there are works in operation, and being built, which by the end of next year will be making calcium cyanamide at the rate of more than a quarter of a million tons per annum.

installations for Manufacture of Calcium Cyanamide by the Franck and Caro Process.

Name of Company.

Nitrogen Fertilizers Co. (Northwestern Cyanamide Co.)

Nitrogen Fertilizers Co. (Northwestern Cyanamide $\mathrm{Co}$.)

Societa Italiana di Prodotti Azotate

Societa Italiana per il Carburo di Calcio

Societa Piemontese per il Carburo di Calcio

Société Française pour les Pro-

duits Azotes

Bayerische Stickstoff Werke

Ost-Deutscher Stickstoff. u

Chemische Werke

A. G. Stickstoffdunger

Societa per l'Utilizzazione delle Forze Idrauliche della Dalmazia

Japanese Nitrogen Products Co.

American Cyanide Co.

The Nitrogen Fertilizers Co., which owns the Odda and Alby Works, works under license from the Northwestern Cyanamide Co., which company controls England, Norway and Sweden, Belgium, and all the British colonies, protectorates and dependencies, except Egypt and Canada. The Odda plant is being enlarged, and at the beginning of next year will be producing 73,000 tons per annum. In the United States, the American Cyanamide $\mathrm{Co}$. is about to erect a works in Alabama to manufacture 24,000 tons per year.

\section{A PROCESS FOR THE FIXATION OF ATMOSPHERIC NITROGEN.}

The Chemical Trade Journal (50, 622) observes that many have assumed a pessimistic attitude on the subject of the fixation of atmospheric nitrogen. This feeling is attributable, in the main, to the fact that the possibilities of the various processes so far devised have been over-popularized, and there can be no doubt as to the ultimate importance of the question. The same Journal notes that the price movements of nitrate of soda show evidence rather of market rigging than of any near approach to the exhaustion of the Chilean deposits. Nevertheless, the great German chemical works are keenly alive to the importance of the problem of nitrogen fixation and each is doing something toward its solution; for example, while the Badische Company have reduced their holding in the Norwegian production to nominal proportions, the German patent list bears evidence of the activity of this concern in endeavoring to devise a suitable process.

In the process for the fixation of atmospheric nitrogen described in the Zentralblatt für de Kunstdungen-Industrie (see Chem. Trade J., loc. cit.), use is made of the fact that the oxides of nitrogen result when mixtures of air with combustible gas are detonated. While this has been known for a long time, the conditions necessary to secure a relatively high yield of nitrous gases has only recently been determined and a commercial plant working on these lines has yet to be erected. The favorable conditions seem to be high pressure, high temperature, and a proportion of oxygen greater than that present in air, that is, an addition of oxygen to the gas mixture is advantageous. It has also been found that previous compression of the gas and air, preferably separately, to 5 atmospheres, notably increases the yield of nitric acid, and that preheating the air and adding 30 per cent. of oxygen have a similar effect. It is said that if these conditions are realized, as much as I2 lbs. of nitric acid per $r, 000 \mathrm{cu}$. ft. of gas may be obtained.

\section{THE CORROSION OF IRON AND STEEL.}

The Chemical Engineer (I5, 246) gives the following summary 